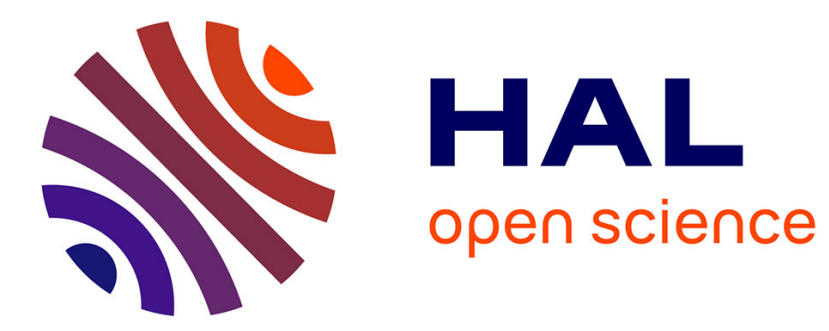

\title{
Epitaxial ferromagnetic oxide thin films on silicon with atomically sharp interfaces
}

Patricia de Coux, R. Bachelet, Bénédicte Warot-Fonrose, V. Skumryev, L. Lupina, G. Niu, T. Schroeder, J. Fontcuberta, F. Sánchez

\section{To cite this version:}

Patricia de Coux, R. Bachelet, Bénédicte Warot-Fonrose, V. Skumryev, L. Lupina, et al.. Epitaxial ferromagnetic oxide thin films on silicon with atomically sharp interfaces. Applied Physics Letters, 2014, 105 (1), pp.012401. 10.1063/1.4887349 . hal-01707028

\section{HAL Id: hal-01707028 \\ https://hal.science/hal-01707028}

Submitted on 23 Feb 2018

HAL is a multi-disciplinary open access archive for the deposit and dissemination of scientific research documents, whether they are published or not. The documents may come from teaching and research institutions in France or abroad, or from public or private research centers.
L'archive ouverte pluridisciplinaire HAL, est destinée au dépôt et à la diffusion de documents scientifiques de niveau recherche, publiés ou non, émanant des établissements d'enseignement et de recherche français ou étrangers, des laboratoires publics ou privés. 


\section{Epitaxial ferromagnetic oxide thin films on silicon with atomically sharp interfaces}

P. de Coux, R. Bachelet, B. Warot-Fonrose, V. Skumryev, L. Lupina, G. Niu, T. Schroeder, J. Fontcuberta, and F. Sánchez

Citation: Appl. Phys. Lett. 105, 012401 (2014); doi: 10.1063/1.4887349

View online: https://doi.org/10.1063/1.4887349

View Table of Contents: http://aip.scitation.org/toc/apl/105/1

Published by the American Institute of Physics

\section{Articles you may be interested in}

Magnetism of $\mathrm{CoFe}_{2} \mathrm{O}_{4}$ ultrathin films on $\mathrm{MgAl}_{2} \mathrm{O}_{4}$ driven by epitaxial strain

Applied Physics Letters 103, 092405 (2013); 10.1063/1.4819178

Domain matching epitaxy of ferrimagnetic $\mathrm{CoFe}_{2} \mathrm{O}_{4}$ thin films on $\mathrm{Sc}_{2} \mathrm{O}_{3} / \mathrm{Si}(111)$

Applied Physics Letters 99, 211910 (2011); 10.1063/1.3663216

Multifunctional epitaxial systems on silicon substrates

Applied Physics Reviews 3, 031301 (2016); 10.1063/1.4955413

Multiferroic heterostructures of $\mathrm{Fe}_{3} \mathrm{O}_{4} / \mathrm{PMN}-\mathrm{PT}$ prepared by atomic layer deposition for enhanced interfacial magnetoelectric couplings

Applied Physics Letters 110, 082902 (2017); 10.1063/1.4976008

Epitaxial c-axis oriented $\mathrm{BaTiO}_{3}$ thin films on $\mathrm{SrTiO}_{3}$-buffered $\mathrm{Si}(001)$ by atomic layer deposition

Applied Physics Letters 104, 082910 (2014); 10.1063/1.4867469

Structure and magnetic properties of epitaxial spinel ferrite thin films

Applied Physics Letters 68, 714 (1996); 10.1063/1.116601

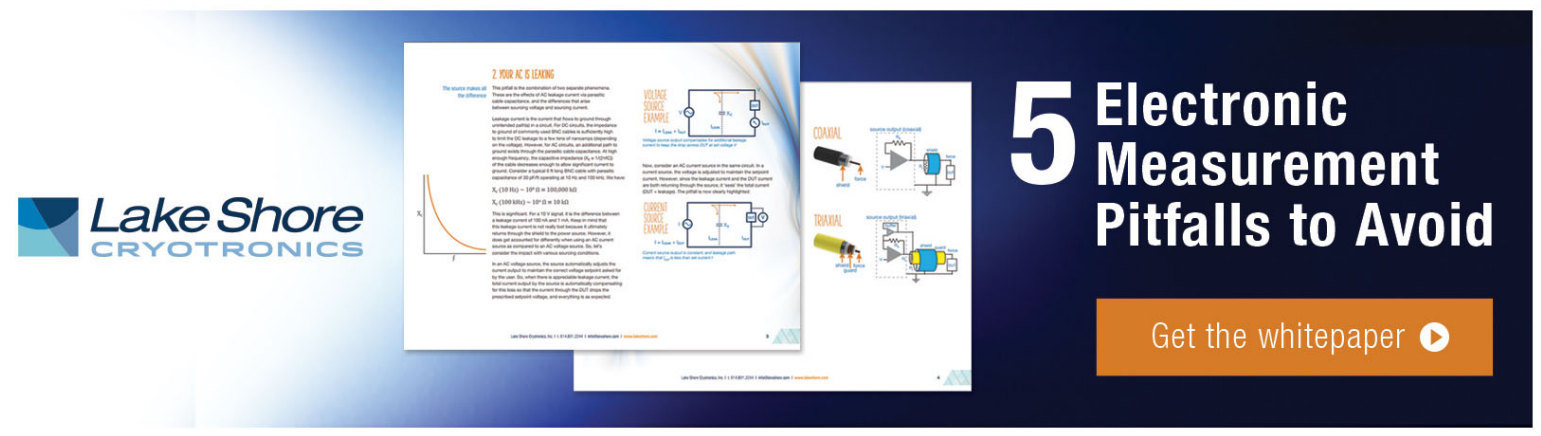




\title{
Epitaxial ferromagnetic oxide thin films on silicon with atomically sharp interfaces
}

\author{
P. de Coux,${ }^{1,2}$ R. Bachelet, ${ }^{1, a)}$ B. Warot-Fonrose,${ }^{2}$ V. Skumryev, ${ }^{3}$ L. Lupina,${ }^{4}$ G. Niu,${ }^{4}$ \\ T. Schroeder, ${ }^{4}$ J. Fontcuberta, ${ }^{1}$ and F. Sánchez ${ }^{1, b)}$ \\ ${ }^{1}$ Institut de Ciència de Materials de Barcelona (ICMAB-CSIC), Campus de la UAB, 08193 Bellaterra, \\ Barcelona, Spain \\ ${ }^{2}$ CEMES-CNRS, 29 rue Jeanne Marvig, BP 94347, Toulouse Cedex 4, France \\ ${ }^{3}$ Institució Catalana de Recerca i Estudis Avançats (ICREA), Barcelona, Spain \\ and Dep. de Física, Univ. Autònoma de Barcelona, 08193 Bellaterra, Spain \\ ${ }^{4}$ IHP, Im Technologiepark 25, 15236 Frankfurt (Oder), Germany
}

(Received 5 June 2014; accepted 24 June 2014; published online 7 July 2014)

\begin{abstract}
A bottleneck in the integration of functional oxides with silicon, either directly grown or using a buffer, is the usual formation of an amorphous interfacial layer. Here, we demonstrate that ferromagnetic $\mathrm{CoFe}_{2} \mathrm{O}_{4}$ films can be grown epitaxially on $\mathrm{Si}(111)$ using a $\mathrm{Y}_{2} \mathrm{O}_{3}$ buffer layer, and remarkably the $\mathrm{Y}_{2} \mathrm{O}_{3} / \mathrm{Si}(111)$ interface is stable and remains atomically sharp. $\mathrm{CoFe}_{2} \mathrm{O}_{4}$ films present high crystal quality and high saturation magnetization. (C) 2014 AIP Publishing LLC.

[http://dx.doi.org/10.1063/1.4887349]
\end{abstract}

Complex oxides, with wide variety of functional properties, are extraordinarily appealing as new materials to improve responses in existing devices, or to develop radically new ones. Indeed, complex oxides are already considered highly relevant emerging materials for the future evolution of microelectronics by the "More than Moore" approach. ${ }^{1}$ However, the success of oxide electronics is conditioned by the bottleneck of the difficult integration of complex oxides with silicon. In spite that oxide electronics constitutes one of the most active research fields in materials science and technology, the integration of complex oxides with silicon still requires substantial progress.

The main cause of the difficult integration of crystalline oxides with silicon is the strong chemical interaction. ${ }^{2}$ Most of complex oxides react strongly with silicon, and direct growth of high quality epitaxial films has been found to be possible in only few cases. ${ }^{3,4}$ Thus, buffer layers are generally necessary, being $\mathrm{SrTiO}_{3}$ or yttria-stabilized zirconia (YSZ) used in most of the cases. These buffers have permitted epitaxial growth with excellent functional properties of relevant oxides including ferroelectric $\mathrm{Bi}_{3.25} \mathrm{La}_{0.75} \mathrm{Ti}_{3} \mathrm{O}_{12}$ (Ref. 5) and $\mathrm{BaTiO}_{3}{ }^{6-8}$ piezoelectric $\mathrm{Pb}\left(\mathrm{Mg}_{1 / 3} \mathrm{Nb}_{2 / 3}\right) \mathrm{O}_{3}-\mathrm{PbTiO}_{3},{ }^{9}$ ferromagnetic manganites, ${ }^{10}$ and spinels, ${ }^{11}$ and high mobility $\mathrm{LaAlO}_{3} / \mathrm{SrTiO}_{3}$ interfaces. ${ }^{12}$ However, the interface between silicon and the $\mathrm{SrTiO}_{3}$ or the YSZ buffer is not stable under the conditions of high substrate temperature and partial pressure of oxygen required for epitaxy of these functional oxides, and the resulting buffer/silicon interface degrades with formation of an amorphous interfacial layer. This degradation is reported in all examples mentioned above. The stability of the interface is a serious problem in some applications, including field-effect and tunnel devices. For such cases, buffer layers with higher chemical stability with silicon are necessary.

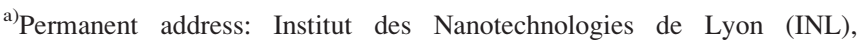
UMR5270 CNRS, Ecole Centrale de Lyon, 36 avenue Guy de Collongue, 69134 Ecully, France.

${ }^{b}$ Author to whom correspondence should be addressed. Electronic mail: fsanchez@icmab.es
}

Here, we report on the use of $\mathrm{Y}_{2} \mathrm{O}_{3}$ as a buffer layer for the epitaxy of ferromagnetic spinel $\mathrm{CoFe}_{2} \mathrm{O}_{4}$ (CFO) on $\mathrm{Si}(111)$. CFO grows by the mechanism of domain matching epitaxy, and presents high crystal quality and high magnetization in spite of the large lattice mismatch of around $21 \%$ with $\mathrm{Y}_{2} \mathrm{O}_{3}$. The $\mathrm{Y}_{2} \mathrm{O}_{3} / \mathrm{Si}$ interface is found to be stable and transmission electron microscopy confirms the absence of an interfacial layer.

$\mathrm{Y}_{2} \mathrm{O}_{3}$ buffer layers were deposited by molecular beam epitaxy on the $7 \times 7$ reconstructed $\mathrm{Si}(111)$. Additional information is reported elsewhere. ${ }^{13}$ The $\mathrm{Y}_{2} \mathrm{O}_{3}$ buffered $\mathrm{Si}(111)$ wafers were cut in small chips and used as substrate to grow CFO films by pulsed laser deposition $(\lambda=248 \mathrm{~nm}$, fluence $\sim 1.5 \mathrm{~J} / \mathrm{cm}^{2}$ ) at $550{ }^{\circ} \mathrm{C}$ substrate temperature. Oxygen pressure was increased progressively until $0.1 \mathrm{mbar}$ as described elsewhere. ${ }^{11}$ Structural characterization was done by reflection high energy electron diffraction (RHEED), X-ray diffraction (XRD), high resolution transmission electron microscopy (HRTEM) in cross-section geometry along the Si[11-2] zone axis (using a spherical aberration corrected FEI-Tecnai microscope at $200 \mathrm{kV}$ ), and atomic force microscopy (AFM) in dynamic mode. Magnetization loops were measured by superconducting quantum interference device (SQUID) magnetometer.

$\mathrm{CFO}$ and $\mathrm{Y}_{2} \mathrm{O}_{3}$ are both cubic with lattice parameters $\mathrm{a}_{\mathrm{CFO}}=8.392 \AA$ and $\mathrm{a}_{\mathrm{Y} 2 \mathrm{O} 3}=10.604 \AA$, respectively. The RHEED pattern (Fig. 1(a)) of the $\mathrm{Y}_{2} \mathrm{O}_{3}$ buffer layer with a thickness ( $\mathrm{t}$ ) of $\mathrm{t}=31 \mathrm{~nm}$, taken along $\mathrm{Si}[11-2]$, shows a high intensity specular spot and Bragg reflections. The intensity decreases immediately as deposition of CFO starts (Fig. 1(b)) and RHEED intensity oscillations were not observed. However, the patterns at the end of the deposition confirmed the epitaxial growth of the film. Figs. 1(c) and 1(d) show the patterns recorded at the end of deposition of the $t=26 \mathrm{~nm}$ CFO film along $\mathrm{Si}[11-2]$ and $\mathrm{Si}[1-10]$, respectively. The patterns are streaky, attesting in-plane crystalline order. This observation provides the first indication that the lattice mismatch, $\mathrm{f}(\%)=100 \times\left(\mathrm{a}_{\mathrm{CFO}}-\mathrm{a}_{\mathrm{Y} 2 \mathrm{O} 3}\right) / \mathrm{a}_{\mathrm{Y} 2 \mathrm{O} 3} \sim-20.9 \%$, does not prevent epitaxy. The modulation of the intensity along 


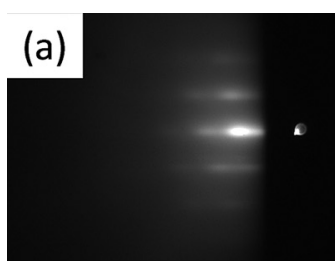

(b)
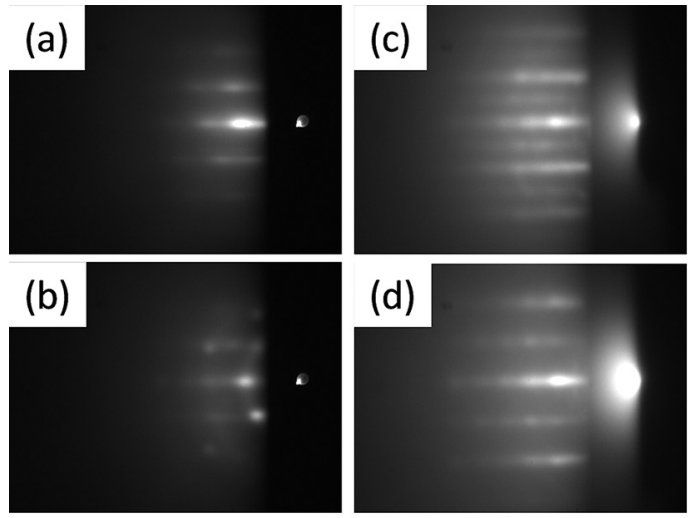

(d)

(f)

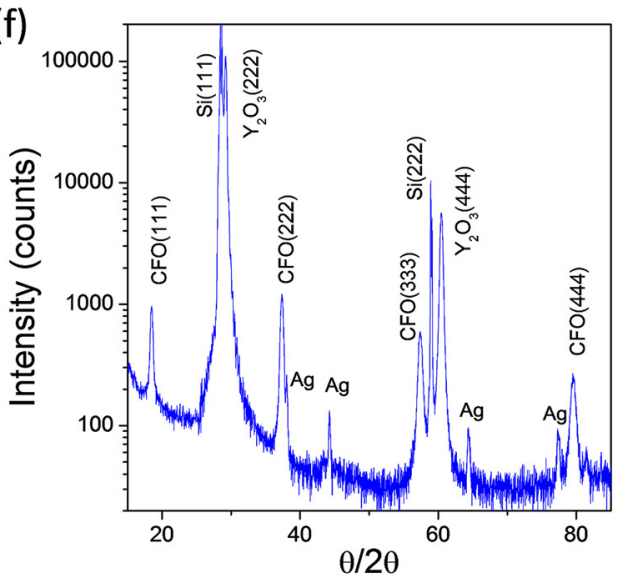

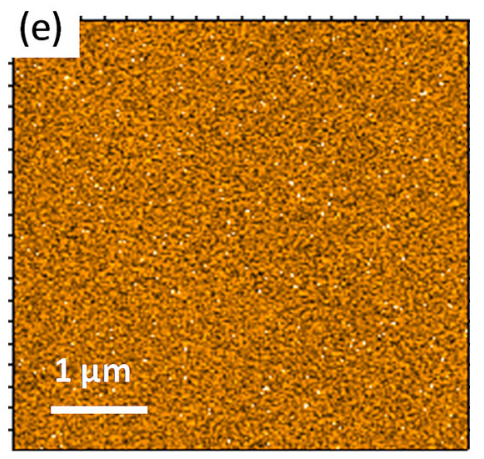

(g)

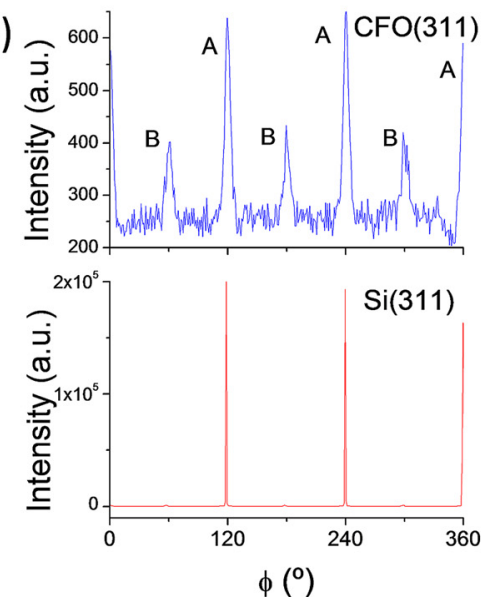

FIG. 1. RHEED patterns taken along the $\mathrm{Si}$ [11-2] direction of (a) $\mathrm{Y}_{2} \mathrm{O}_{3}$ buffer layer, (b) early stage of CFO growth $(t=2-3 \AA)$, and (c) at the end $(t=26 \mathrm{~nm})$ of deposition. (d) RHEED pattern at the end of the deposition along $\mathrm{Si}[1-10]$. (f) XRD $\theta-2 \theta$ scan and (g) XRD $\phi$-scan around (311) reflections of CFO (top panel) and Si (bottom panel). the streaks suggests certain film roughness. The AFM image in Fig. 1(e) shows an homogeneous surface with dense granular morphology, being the grain size smaller than $100 \mathrm{~nm}$ and the root-mean square (rms) roughness is smaller than $5 \AA$. The XRD $\theta-2 \theta$ scan around symmetrical reflections (Fig. 1(f)) shows (lll) reflections from $\mathrm{Si}, \mathrm{Y}_{2} \mathrm{O}_{3}$, and $\mathrm{CFO}$. There are no peaks corresponding to other reflections from $\mathrm{CFO}$ or $\mathrm{Y}_{2} \mathrm{O}_{3}$ (the narrow peaks of smaller intensity correspond to the silver used to glue the substrate, not removed from the lateral sides of the sample). Thus, $\mathrm{CFO} / \mathrm{Y}_{2} \mathrm{O}_{3} / \mathrm{Si}(111)$ is fully (lll) oriented with absence of spurious crystalline phases. The outof-plane lattice parameters of $\mathrm{CFO}$ and $\mathrm{Y}_{2} \mathrm{O}_{3}$ are $4.848 \AA$ and $6.122 \AA$, respectively, coincident with bulk values and thus point to relaxed films structures. The $\phi$-scans around (311) reflections of CFO and $\mathrm{Si}$, presented in Fig. 1(g), confirm that the CFO film is epitaxial. There are two sets of three $\mathrm{CFO}(311)$ peaks, indicating coexistence of two in-plane crystal variants. The set with higher intensity, at the same $\phi$ positions as the Si reflections, is usually known as A-type orientation. ${ }^{13}$ The smaller intensity peaks $60^{\circ}$ apart from the A-type set correspond to the same crystal structure of CFO but rotated $180^{\circ}$ in the plane and is usually known as B-type orientation. Considering the intensity of both sets of peaks the fraction of minority $\mathrm{B}$ variant can be roughly estimated to be around $30 \%$. In contrast, the $\mathrm{Y}_{2} \mathrm{O}_{3}$ films present a single B-type variant. ${ }^{13}$ Thus, the epitaxial relationships of the $\mathrm{A}$ and $\mathrm{B}$ type $\mathrm{CFO}$ crystal variants respect $\mathrm{Y}_{2} \mathrm{O}_{3}$ and $\mathrm{Si}$ correspond, respectively, to [11-2]CFO(111)//[-1-12] $\mathrm{Y}_{2} \mathrm{O}_{3}(111) / /$ [11-2] $\mathrm{Si}(111)$, and $[-1-12] \mathrm{CFO}(111) / /[11-2] \mathrm{Y}_{2} \mathrm{O}_{3}(111) / /$ [11-2]Si(111).

The epitaxy mechanisms of $\mathrm{CFO}$ on $\mathrm{Y}_{2} \mathrm{O}_{3}$ and the sharpness of $\mathrm{CFO} / \mathrm{Y}_{2} \mathrm{O}_{3}$ and $\mathrm{Y}_{2} \mathrm{O}_{3} / \mathrm{Si}$ interfaces have been investigated by TEM. In Fig. 2(a), we present a HRTEM image around the $\mathrm{CFO} / \mathrm{Y}_{2} \mathrm{O}_{3}$ interface (marked by arrows). Both
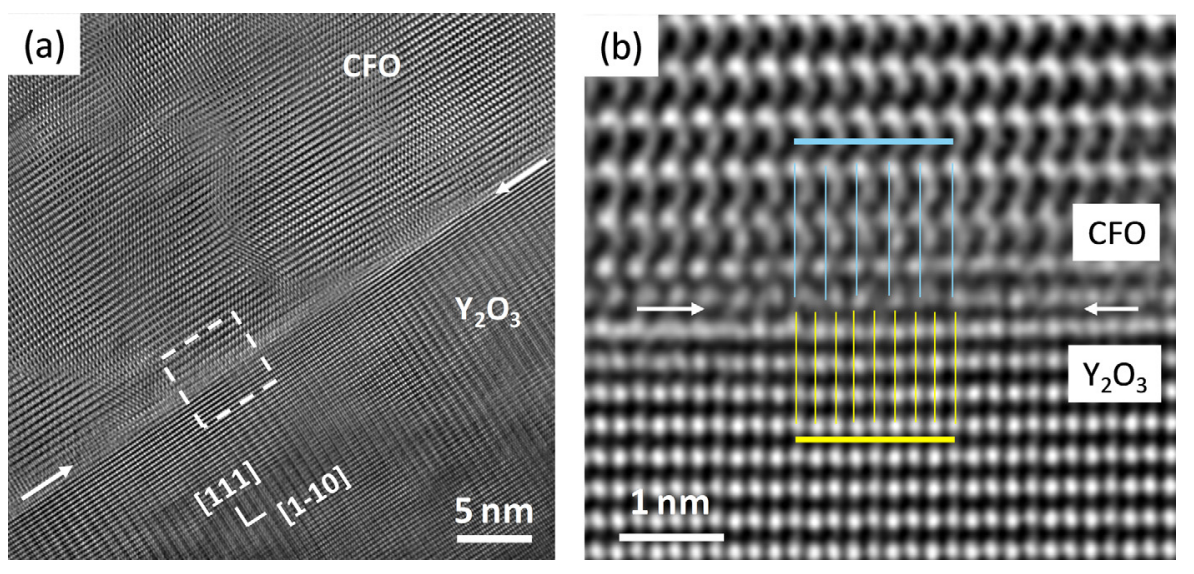

FIG. 2. (a) Cross section HRTEM image along [11-2] zone axis around the $\mathrm{CFO} / \mathrm{Y}_{2} \mathrm{O}_{3}$ interface. The arrows mark the interface. (b) Zoom of the region marked in (a). Yellow and light blue vertical lines mark $\mathrm{Y}_{2} \mathrm{O}_{3}$ and $\mathrm{CFO}$ planes, respectively. The domain length is indicated by the horizontal lines. 

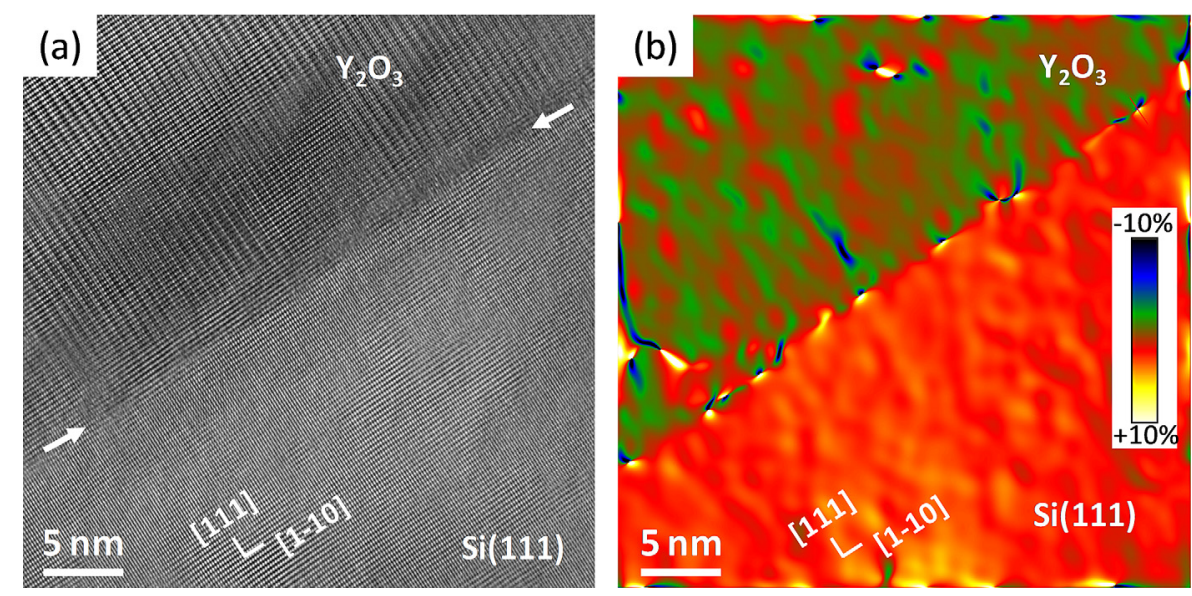

FIG. 3. (a) Cross section HRTEM image along [11-2] zone axis around the $\mathrm{Y}_{2} \mathrm{O}_{3} / \mathrm{Si}$ interface. The arrows mark the interface. The corresponding map of the in-plane strain of $\mathrm{Y}_{2} \mathrm{O}_{3}$ with respect to $\mathrm{Si}$ is in (b). layers are homogeneous and present high structural quality, without signs of chemical interaction or incoherent areas at the interface. The absence of disorder is remarkable considering the large lattice mismatch. The region around the interface marked with the dashed line in Fig. 2(a) is zoomed in Fig. 2(b). Vertical lines (light blue for planes in $\mathrm{CFO}$ and yellow for planes in $\mathrm{Y}_{2} \mathrm{O}_{3}$ ) are drawn to visualize better the epitaxy. It is appreciated that five planes in $\mathrm{CFO}$ match with eight lattice planes in $\mathrm{Y}_{2} \mathrm{O}_{3}$, according with the so called domain matching epitaxy mechanism. ${ }^{14}$ The domain formed by the 5 atomic planes of CFO is $14.84 \AA$ long and the one with 8 planes of $\mathrm{Y}_{2} \mathrm{O}_{3} 15.0 \AA$, being the mismatch of only around $-1.1 \%$, permitting epitaxy. A similar mechanism of domain matching epitaxy has been also observed in CFO films on $\mathrm{Sc}_{2} \mathrm{O}_{3} / \mathrm{Si}(111) .{ }^{15}$

A HRTEM image around the $\mathrm{Y}_{2} \mathrm{O}_{3} / \mathrm{Si}(111)$ interface is shown in Fig. 3(a). The interface, marked by arrows, is very abrupt and without any interfacial layer. The absence of an interfacial layer was confirmed in all regions analyzed by HRTEM. The sharpness of the $\mathrm{Y}_{2} \mathrm{O}_{3} / \mathrm{Si}(111)$ interface had been already reported, ${ }^{13}$ and our results prove that it is stable after deposition of the CFO film. This is an outstanding result since the interface between a crystalline oxide and $\mathrm{Si}$ usually degrades under the conditions required for subsequent epitaxial growth of complex oxides. Indeed, a $\mathrm{SiO}_{x}$ interfacial layer was present in $\mathrm{CFO} / \mathrm{Sc}_{2} \mathrm{O}_{3} / \mathrm{Si}(111)$ samples. ${ }^{15}$ The sharpness of the $\mathrm{Y}_{2} \mathrm{O}_{3} / \mathrm{Si}(111)$ interface is also evident in the corresponding map of the in-plane strain of

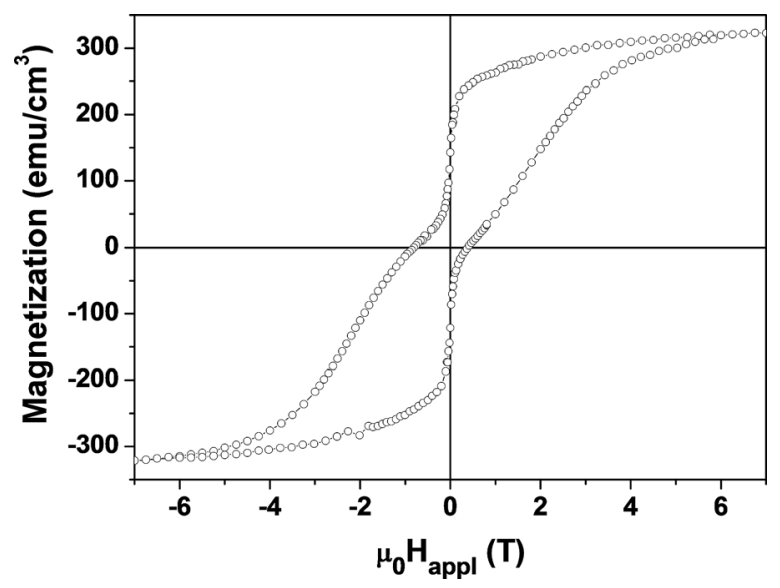

FIG. 4. Magnetization loop at $10 \mathrm{~K}$ with the field applied in-plane of the film, along Si[1-10].
$\mathrm{Y}_{2} \mathrm{O}_{3}$ with respect to $\mathrm{Si}$ (Fig. 3(b)), determined using as reference a zone of the silicon substrate and obtained by geometrical phase analysis. ${ }^{16}$ It indicates a homogeneous strain around $-2.4 \%$ which corresponds to full relaxation of $\mathrm{Y}_{2} \mathrm{O}_{3}$. Also, some interfacial dislocations shown by local deformation fields are well visualized.

Figure 4 shows a magnetization loop measured at $10 \mathrm{~K}$ with the field applied in the plane of the sample, along the Si[1-10] direction. The shrinking at low fields is characteristic of magnetization loops of ferromagnetic spinel film. ${ }^{17-19}$ The saturation magnetization is around $320 \mathrm{emu} / \mathrm{cm}^{3}$, slightly lower than the bulk value of around $400 \mathrm{emu} / \mathrm{cm}^{3}$ and similar to the magnetization of CFO films grown on perovskite substrates. ${ }^{18,20}$

In summary, $\mathrm{Y}_{2} \mathrm{O}_{3}$ buffer layers permit epitaxial integration of spinel ferromagnetic $\mathrm{CFO}$ with $\mathrm{Si}(111)$. CFO grows epitaxially in spite of the huge lattice mismatch above $20 \%$. It occurs by the mechanism of domain matching epitaxy and suggests opportunities of integration of other functional oxides with silicon by using highly mismatched buffer layers. The interface between $\mathrm{Y}_{2} \mathrm{O}_{3}$ and $\mathrm{Si}(111)$ is stable and remains atomically sharp after $\mathrm{CFO}$ deposition. It points to high potential of ultrathin $\mathrm{CFO} / \mathrm{Y}_{2} \mathrm{O}_{3}$ bilayers for fabrication of spintronic tunnel devices.

Financial support by the Spanish Government [Projects MAT2011-29269-C03 and NANOSELECT CSD200700041] and Generalitat de Catalunya (2009 SGR 00376) is acknowledged.

${ }^{1}$ Y. Fujisaki, Jap. J. Appl. Phys. 49, 100001 (2010).

${ }^{2}$ J. P. Locquet, C. Marchiori, M. Sousa, J. Fompeyrine, and J. W. Seo, J. Appl. Phys. 100, 051610 (2006).

${ }^{3}$ J. W. Reiner, A. M. Kolpak, Y. Segal, K. F. Garrity, S. Ismail-Beigi, C. H. Ahn, and F. J. Walker, Adv. Mater. 22, 2919 (2010).

${ }^{4}$ S. H. Baek and C. B. Eom, Acta Mater. 61, 2734 (2013).

${ }^{5}$ H. N. Lee, D. Hesse, N. Zakharov, and U. Gösele, Science 296, 2006 (2002); H. N. Lee, S. Senz, N. D. Zakharov, C. Harnagea, A. Pignolet, D. Hesse, and U. Gösele, Appl. Phys. Lett. 77, 3260 (2000).

${ }^{6}$ M. Scigaj, N. Dix, I. Fina, R. Bachelet, B. Warot-Fonrose, J. Fontcuberta, and F. Sánchez, Appl. Phys. Lett. 102, 112905 (2013).

${ }^{7}$ S. Abel, T. Stöferle, C. Marchiori, C. Rossel, M. D. Rossell, R. Erni, D. Caimi, M. Sousa, A. Chelnokov, B. J. Offrein, and J. Fompeyrine, Nat. Commun. 4, 1671 (2013).

${ }^{8}$ C. Dubourdieu, J. Bruley, T. M. Arruda, A. Posadas, J. Jordan-Sweet, M. M. Frank, E. Cartier, D. J. Frank, S. V. Kalinin, A. A. Demkov, and V. Narayanan, Nat. Nanotechnol. 8, 748 (2013). 
${ }^{9}$ S. H. Baek, J. Park, D. M. Kim, V. A. Aksyuk, R. R. Das, S. D. Bu, D. A. Felker, J. Lettieri, V. Vaithyanathan, S. S. N. Bharadwaja, N. BassiriGharb, Y. B. Chen, H. P. Sun, C. M. Folkman, H. W. Jang, D. J. Kreft, S. K. Streiffer, R. Ramesh, X. Q. Pan, S. Trolier-McKinstry, D. G. Schlom, M. S. Rzchowski, R. H. Blick, and C. B. Eom, Science 334, 958 (2011).

${ }^{10}$ P. Perna, L. Méchin, M. P. Chauvat, P. Ruterana, Ch. Simon, and U. Scotti di Uccio, J. Phys. Condens. Matter 21, 306005 (2009).

${ }^{11}$ R. Bachelet, P. de Coux, B. Warot-Fonrose, V. Skumryev, J. Fontcuberta, and F. Sánchez, J. Appl. Phys. 110, 086102 (2011).

${ }^{12}$ J. W. Park, D. F. Bogorin, C. Cen, D. A. Felker, Y. Zhang, C. T. Nelson, C. W. Bark, C. M. Folkman, X. Q. Pan, M. S. Rzchowski, J. Levy, and C. B. Eom, Nat. Commun. 1, 94 (2010).

${ }^{13}$ L. Tarnawska, A. Giussani, P. Zaumseil, M. A. Schubert, R. Paszkiewicz, O. Brandt, P. Storck, and T. Schroeder, J. Appl. Phys. 108, 063502 (2010).
${ }^{14}$ J. Narayan and B. C. Larson, J. Appl. Phys. 93, 278 (2003).

${ }^{15}$ F. Sánchez, R. Bachelet, P. de Coux, B. Warot-Fonrose, V. Skumryev, L. Tarnawska, P. Zaumseil, T. Schroeder, and J. Fontcuberta, Appl. Phys. Lett. 99, 211910 (2011).

${ }^{16}$ M. J. Hytch, E. Snoeck, and R. Kilaas, Ultramicroscopy 74, 131 (1998).

${ }^{17}$ B. D. Cullity and C. D. Graham, Introduction to Magnetic Materials, 2nd ed. (John Wiley \& Sons, Hoboken, New Jersey, USA, 2009).

${ }^{18}$ F. Rigato, J. Geshev, V. Skumryev, and J. Fontcuberta, J. Appl. Phys. 106, 113924 (2009).

${ }^{19}$ R. G. S. Sofin, H. C. Wu, and I. V. Shvets, Phys. Rev. B 84, 212403 (2011).

${ }^{20}$ J. M. Rebled, M. Foerster, S. Estradé, F. Rigato, C. Kanamadi, F. Sánchez, F. Peirò, and J. Fontcuberta, Phys. Chem. Chem. Phys. 15, 18274 (2013). 